\title{
Live Virus Vaccines in Transplantation: Friend or Foe?
}

\author{
Charlotte M. Verolet • Klara M. Posfay-Barbe
}

Published online: 14 April 2015

(C) Springer Science+Business Media New York 2015

\begin{abstract}
Solid organ and hematopoietic stem cell transplant recipients may be exposed to diseases which may be prevented through live attenuated virus vaccines (LAVV). Because of their immunosuppression, these diseases can lead to severe complications in transplant recipients. Despite increasing evidence regarding the safety and effectiveness of certain LAVV, these vaccines are still contraindicated for immunocompromised patients, such as transplant recipients. We review the available studies on LAVV, such as varicella zoster, measles-mumps-rubella, influenza, yellow fever, polio, and Japanese encephalitis vaccines in transplant patients. We discuss the current recommendations and the potential risks, as well as the expected benefits of LAVV immunization in this population.
\end{abstract}

Keywords Live attenuated vaccine $\cdot$ Varicella $\cdot$ Herpes zoster · Measles · Mumps · Rubella · Influenza · Yellow fever · Polio · Japanese encephalitis · Immunosuppression · Solid organ transplant $\cdot$ Hematopoietic stem cell transplant . Immunity $\cdot$ Adverse events

This article is part of the Topical Collection on Transplant and Oncology

C. M. Verolet $\cdot$ K. M. Posfay-Barbe

Pediatric Infectious Diseases Unit, Division of General Pediatrics, Department of Pediatrics, University Hospitals of Geneva \& University of Geneva Medical School, Geneva, Switzerland

C. M. Verolet

e-mail: Charlotte.Verolet@hcuge.ch

C. M. Verolet $\cdot$ K. M. Posfay-Barbe $(\bowtie)$

Children's Hospital of Geneva, University Hospitals of Geneva, 6, Rue Willy-Donzé, 1211 Geneva 14, Switzerland

e-mail: Klara.PosfayBarbe@hcuge.ch

\section{Introduction}

For the last three decades, the number of solid organ transplants (SOT) and hematopoietic stem cell transplants (HSCT) performed has increased worldwide. In parallel, the patients' outcomes, as well as quality of life, have significantly improved over time not only because of better surgical techniques and a better use of prophylactic antimicrobials but also because of improved immunosuppressive treatments to avoid graft rejection [1]. In solid organ transplantation, patients are most immunosuppressed during the first 6 months after transplantation and immunosuppression decreases progressively during the first year [1, 2]. By contrast, in HSCT recipients, the degree of immunosuppression varies according to the underlying disease or the treatment protocol [3]. The reconstitution of the immune system may take several months to years after transplantation depending on the development - among other things - of graft-versus-host disease (GVHD) [4].

Immunosuppressive drugs target several parts of the humoral and cellular immune systems and are used to induce and maintain a specific immune response [1,2]. This inhibition is not selective to prevent graft rejection but also inhibits the normal immune response to infections. As a consequence, patients with chronically depressed immune function are at a high risk for infections [1,5]. Infections are a common cause of rehospitalization and morbidity after transplantation and can also trigger allogeneic reactions leading to graft rejection and/or death [6]. Prevention of infection with vaccines is therefore one of the easiest, longest lasting ways to reduce the risk of viral or bacterial infections to which transplant recipients are exposed. However, for efficient vaccine response, the immune system has to be sufficiently restored (i.e., immunosuppressive regimen should be low), and vaccination is therefore rarely recommended before 6 months following transplantation $[7,8 \bullet \bullet$. Non-live vaccines are considered safe after transplantation, and seroresponse mostly 
depends on the patient's immune capacity $[9,10]$. Live attenuated virus vaccines (LAVV), by contrast, are currently not recommended by most transplant societies after SOT and recommended only at least 2 years after HSCT [8••]. In this review, we will discuss the currently available literature on LAVV in SOT and HSCT recipients.

\section{Live Attenuated Viral Vaccines}

Humoral immunity is very efficient against extracellular pathogens, while cellular immunity provides protection against intracellular pathogens, such as viruses [11]. However, a collaboration between the two types of immunity is necessary against several microorganisms $[12,13]$. Protection against viruses can be induced by LAVV. These vaccines are called attenuated because the "wild" virus is modified to become less virulent [11]. This is produced either by repeated culturing in animals (or embryo), primary cell cultures or by reassortment of genes from related non-human viruses that are then added to a backbone. LAVV stimulate both humoral and cellular immunity in a fashion similar to actual infection [12]. This makes it a very efficient vaccine in the general population. However, there is a theoretical possibility that the vaccine viral strain reverts to its pathogenic form and causes serious illness, especially in immunocompromised patients [11]. Therefore, LAVV are generally contraindicated in these patients $[8 \cdot \bullet]$. LAVV include live attenuated intranasal influenza vaccine (LAIV), varicella zoster, zoster, measles, mumps, rubella, rotavirus, yellow fever, oral polio, and Japanese encephalitis vaccines.

\section{General Live Attenuated Virus Vaccine Recommendations in Solid Organ Transplant}

Guidelines in different countries regarding LAVV immunization in SOT recipients are remarkably similar, despite differences in virus prevalence, age of patients, and type of transplanted organ $[8 \cdot \bullet, 14]$. In general, LAVV are recommended after 1 year of age. In very young patients and when protection has to be induced rapidly, an accelerated immunization schedule can be offered $[6,8 \cdot \bullet]$. The guidelines agree that LAVV should be given before transplantation, when the immune system still may trigger an optimal and safe immune response to vaccination. It is now recognized that SOT candidates, as young as 6- to 9-month-old, could be vaccinated with LAVV and that vaccines should be administered at least 1 month before the transplantation [8••, 15-17]. Despite these recommendations, there are many missed opportunities leading to insufficient protection in SOT candidates $[15,18]$. Studies showed that immunization before SOT reduces morbidity in pediatric recipients and increases protective titers in comparison with post-transplant primary vaccination $[6,19,20]$. Moreover, in the post-transplant period, a booster vaccination is immunologically more efficient than a primary vaccination $[19,21,22]$. Therefore, the vaccination schedule should be reviewed as soon as transplantation is considered. In addition, because protective antibody levels decrease over time, these levels should be checked during the long-term care of transplant recipients and re-vaccination performed when necessary [18, 23]. In addition, all family members, including siblings, should be evaluated and vaccinated to contribute to the herd immunity of the transplant candidate or recipient $[8 \cdot \bullet]$.

We will discuss below in detail the available interventional studies looking at the use of LAVV after SOT (summarized in Table 1).

\section{General Live Attenuated Virus Vaccine Recommendations in Hematopoietic Stem Cell Transplantation}

International guidelines for LAVV immunization are available for HSCT patients [24, 25]. Before transplantation, the recommendations are the same as for SOT recipient: vaccination starting at 6-9 months of age and at least 1 month before HSCT $[8 \bullet \bullet, 26]$. However, this delay in transplantation is often impossible, and the patients are also frequently highly immunosuppressed during this waiting time. Furthermore, even if they were fully immunized before transplantation, patients usually lose their vaccine-induced immunity after HSCT [27].

It is currently recommended that LAVV are administered 2 years after HSCT if the patient is off immunosuppressive medications, without GVHD and at least 8-11 months after the last intravenous immunoglobulin treatment $[8 \cdot \bullet, 24$, 28-30]. It is more likely that 2 years after HSCT, patients have a proper immunological response to LAVV, and the risk-benefit ratio for vaccinating is therefore favorable [31]. We will discuss below in detail the available interventional studies looking at the use of LAVV following HSCT (summarized in Table 2).

\section{Varicella Zoster Vaccine}

Primary varicella zoster virus (VZV) infection, called chickenpox, causes vesicles and mild fever by infecting epithelial, mononuclear, and ganglia cells. The virus then becomes latent in the dorsal root ganglia cells and can sometimes reactivate at a later time, leading to shingles or herpes zoster, a painful skin rash with blisters in one or several dermatoma 


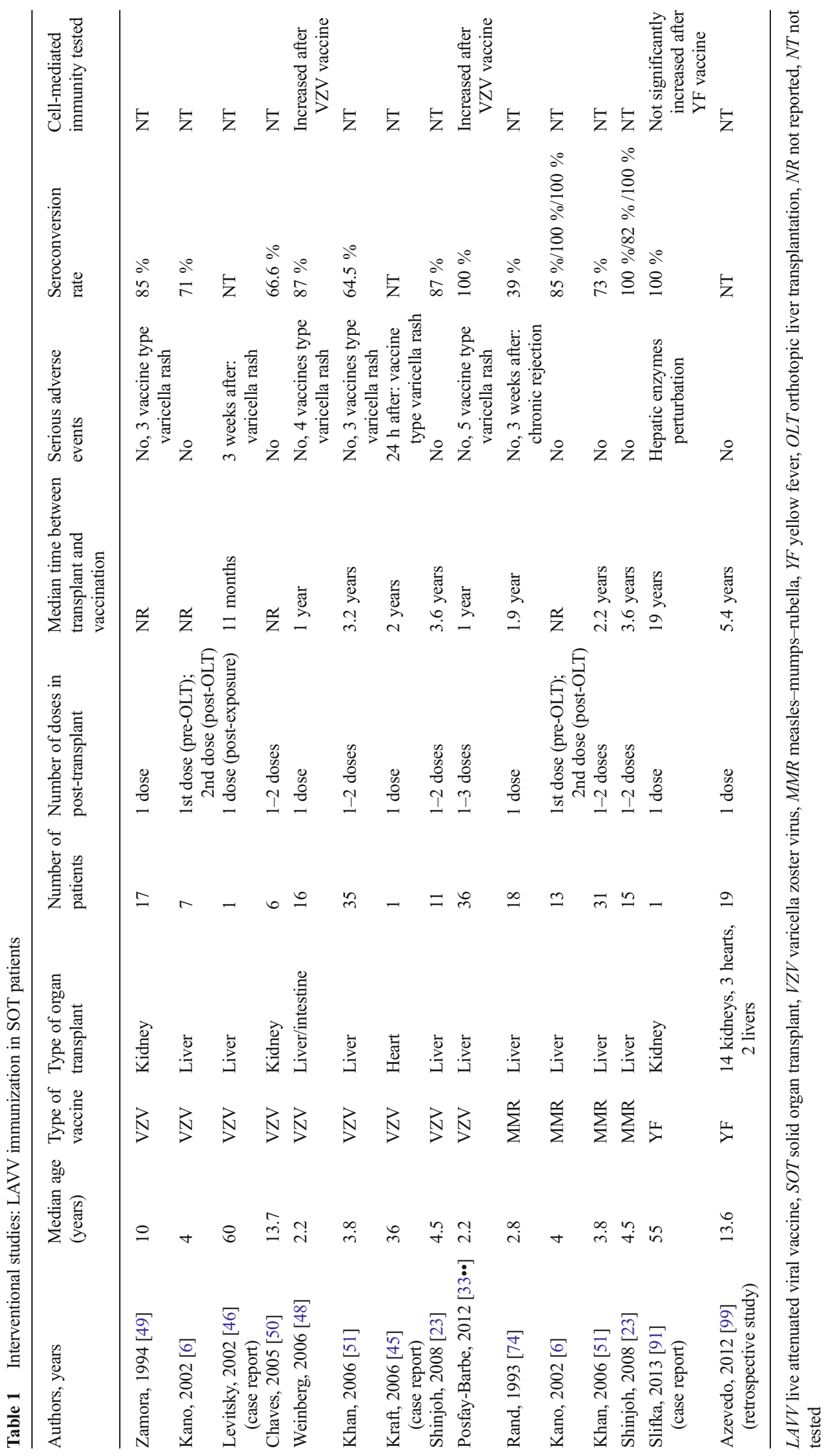




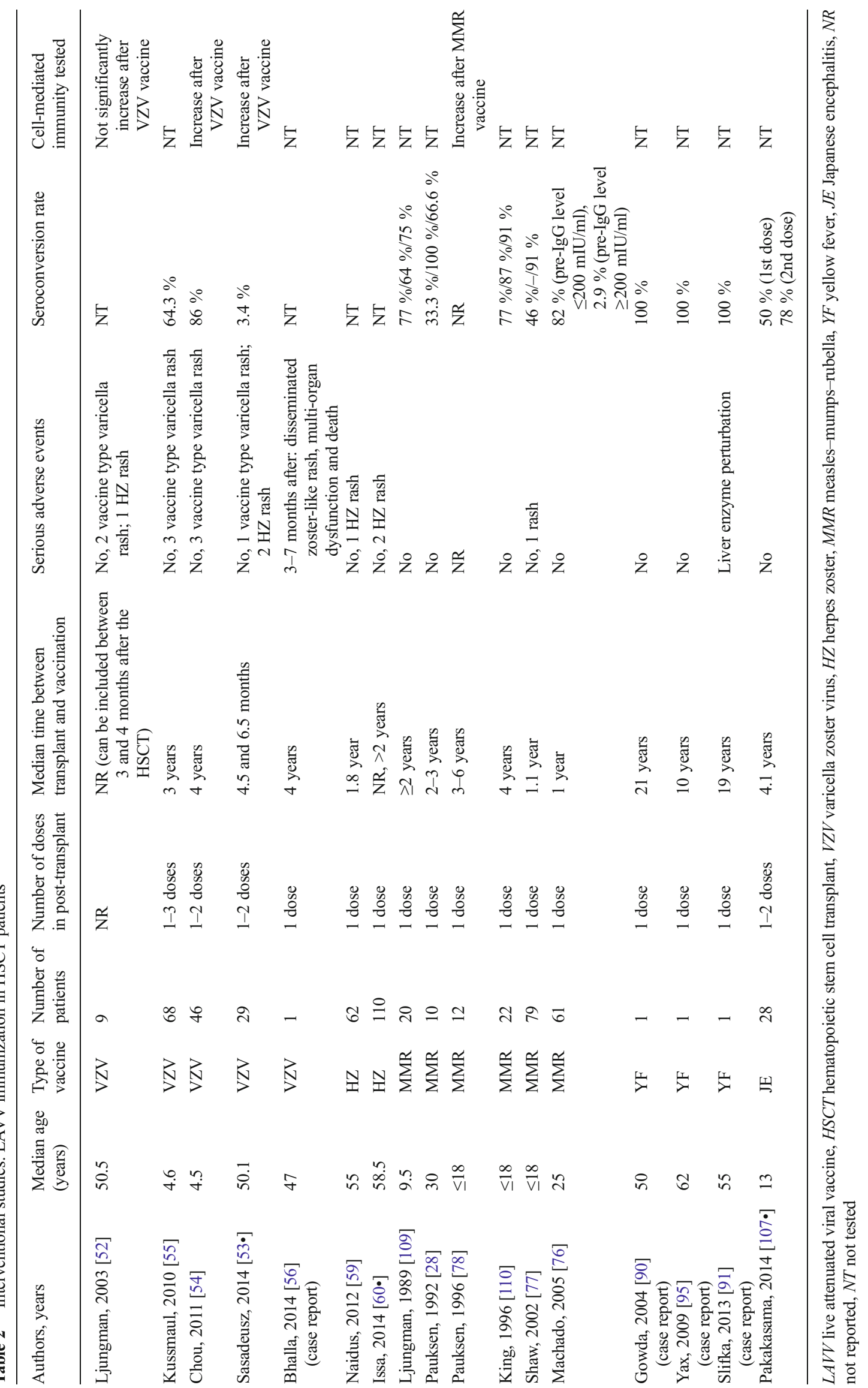


[32]. Varicella is a highly infectious agent and can spread rapidly in a susceptible population $[33 \bullet \bullet, 34]$. VZV complications in SOT recipient may occur in several ways [35]: it can cause severe disseminated disease, allograft rejection, and/or death $[1,5,20,36-39]$. Treatment options to prevent complications in exposed high-risk individuals include the administration of hyperimmune, specific VZV gamma globulin (VZIG) within $96 \mathrm{~h}$ of exposure, and antivirals, such as acyclovir, usually used when disease is suspected $[16,40]$.

The LAVV against VZV has been licensed since 1995 in the USA, with a substantial decrease in the incidence of chickenpox [41]. This vaccine uses VZV's attenuated Oka strain and activates both cellular and humoral host responses, leading to a high seroconversion rate [33••, 42]. This vaccine is administered in two doses, 4 weeks apart to children as young as 9 months of age [32]. Adults usually receive one dose and serological confirmation is optional in healthy individuals [32]. As expected, chickenpox occurs significantly less frequently and with less complications in seropositive SOT recipients, compared with those who never received the vaccine or without a history of chickenpox [15, 43, 44]. Despite isolated case reports suggesting that varicella vaccine is not always safe in transplant recipients [45, 46], several studies have shown that it may be safe and efficient in selected SOT recipients, with close monitoring during and after immunization [7, 18, 21, 32, 47]. Between 1994 and 2012, seven prospective interventional studies of VZV vaccine in SOT pediatric recipients have been published. In total, 128 children were immunized (23 kidney transplants, 103 liver transplants, one liver and small bowel transplant, one small bowel transplant). The rate of seroprotection after vaccination was between 65 and $100 \%$. Two studies also have measured cellular immunity before and after VZV immunization and have shown a significant increase in VZV cell-mediated immunity $[33 \bullet \bullet, 48]$. In all these studies, there were no serious adverse events following vaccination $[6,23,33 \cdot \bullet, 48-51]$.

Regarding the HSCT recipients, even if VZV immunization may be safe 6 months after the transplantation [52], it may be ineffective and does not trigger cellular or humoral response [53•]. However, when patients are immunized 2 years after the HSCT, VZV vaccine seroconversion rates appear to reach approximately the same level as in immunocompetent hosts [54, 55]. Recently, a case report described an extremely rare complication of VZV immunization in an HSCT recipient vaccinated 4 years post-transplantation, despite being diagnosed with a new low-grade lymphoma. Within 3 months of vaccination, he developed a persistent disseminated zoster caused by an acyclovir-resistant vaccine virus and subsequently died [56].

Therefore, it is essential to consider VZV immunization in SOT and HSCT recipients only in selected patients after carefully reviewing their health and immune status.

\section{Herpes Zoster Vaccine}

Shingles is the result of a VZV reactivation and occurs in up to $20 \%$ of patients after SOT or HSCT, a rate that far exceeds what is typical of the general population $(0.4 \%)$ [57]. Its severity varies from a painful, blistering dermatomal eruption to a severe, sometimes fatal, form with cutaneous or visceral dissemination $[1,7,36,58]$. The reactivation is linked to the decline of VZV-specific T cells due to immunosuppressive treatments, age, or other factors [1]. The herpes zoster (HZ) vaccine, recommended in $\geq 50$ years old immunocompetent individuals with a history of chickenpox, uses 14 times higher OKA strain concentrations than in the VZV vaccine and is contraindicated in SOT or HSCT recipients [47]. No data are currently available regarding the $\mathrm{HZ}$ vaccine in SOT recipients. Two recent interventional studies reported the safety of $\mathrm{HZ}$ vaccine in HSCT recipients 2 years after the transplantation but without evaluating the seroconversion rate [59, 60•].

Two new non-LAVV HZ vaccines could become an interesting alternative in shingles prevention in immunocompromised patient. The first, a heat-inactivated varicella vaccine, has been tested in HSCT recipients and shows safety and an increase in VZV-specific cell-mediated immunity [57, 61, 62]. Studies are ongoing in kidney transplant recipients and will hopefully give new insight in the near future [7]. The second vaccine is a recombinant vaccine and has recently been tested in HSCT recipients in a phase $1 / 2$ clinical trial. This recombinant $\mathrm{HZ}$ vaccine appears to be safe and effective and could be administered 50-70 days after the HSCT transplant [63]. These two vaccines could therefore be interesting alternatives for HSCT and SOT recipients.

\section{Measles-Mumps-Rubella Vaccine}

Measles is one of the most contagious epidemic diseases, with 20 million cases per year worldwide [64, 65]. Outbreaks are frequent even in countries in which vaccination is available when vaccine coverage is poor [16]. For example, in the USA in 2014, a total of 644 confirmed measles cases in 27 states were reported [65]. In January 2015, already 68 cases have been declared to the Centers for Disease Control and Prevention [66]. Complications of measles include pneumonia, encephalitis, and subacute sclerosing panencephalitis, which may occur after a latent period of several years [5, 64].

In SOT recipients, complications are more frequent than in healthy hosts and have been described in case reports leading to organ rejection or even death $[16,64,67,68]$. Measles can also have an atypical presentation in immunocompromised patients with an absence of the usual rash [67].

No specific treatment for measles is available, and in case of a contact with measles in the community, passive immunization with non-specific immunoglobulins can be offered. 
This treatment reduces the risk of complication by $76 \%$ in immunocompetent patients and has not been yet measured in high-risk populations, such as in immunocompromised patients [69].

Mumps and rubella are usually benign or mild diseases in immunocompetent hosts.

Mumps infection is characterized by bilateral parotitis and sometimes with orchitis and meningoencephalitis [70]. Rubella usually presents with a rash, lymphadenopathy, fever, and is mostly feared because of its devastating effect on the fetus when acquired during pregnancy [71]. However, little is known on the course of these two diseases in SOT and HSCT recipients. Case reports describe renal graft rejection and death in HSCT recipients following mumps infection, while mild, unspecific illness caused by rubella following liver transplant has been published $[20,70,72]$.

Measles-mumps-rubella (MMR), a combination LAVV, became available in 1963. Thanks to this vaccine, several countries eliminated measles, epidemic mumps, and congenital rubella, by inducing specific, lifelong cell-mediated and humoral immunity [73]. Vaccinating immunocompromised patients could be, in theory, a good way to protect this population against these diseases [64].

In SOT candidates, patients as young as 6-9 months of age should be vaccinated if possible. Seronegative adult candidates should receive one dose of MMR vaccine and be tested for serologic response following vaccination [32]. Evidence regarding the safety of MMR vaccine in pediatric SOT recipients is emerging $[6,23,51,74]$. However, no data are available in adults [47]. To date, four prospective studies about measles immunization have been published, all in pediatric liver transplant recipients. In total, 72 children were immunized and seroconversion rates were between 41 and $100 \%$ $[6,23,51,74]$. No serious adverse events were reported. However, only humoral immunity was measured, and no data are available regarding the cellular immune response. Moreover, gradual waning of antibodies is described, suggesting that it is important to follow-up on antibody response to confirm lasting seroprotection. Only two of these four previous studies (17 pediatric liver transplant recipients) reported mumps and rubella IgG response after MMR immunization with seroconversion rates of $100 \%$ for mumps and $86-100 \%$ for rubella $[6,23]$.

In HSCT recipients, guidelines recommend the use of MMR vaccine in seronegative patients 2 years after the transplantation and without immunosuppression [73, 74]. In 1997, during a measles outbreak, a significant proportion of HSCT patients were susceptible to measles, and 8 of the 54 susceptible patients had measles, for an attack rate of $14.8 \%$ [75]. Prospective studies on immunized HSCT recipients still with immunosuppressive treatment early after transplantation showed that MMR vaccine seems safe, but seroconversion rates varied around 46 and $82 \%$, depending on the preexisting measles antibody levels before immunization [28, 76-78]. Measles serology should therefore be measured during the first 2 years following HSCT, and early immunization should be considered when there is a measles outbreak $[76,77]$.

\section{Influenza Vaccine}

Influenza is a major cause of hospitalization in both competent and immunocompromised patients [2]. This infection can cause severe complications, such as graft rejection and death secondary to pneumonia in SOT recipients and GVHD or airflow obstruction in HSCT recipients [79, 80••]. Although the risk of severe influenza infections and complications is highest early post-transplant, enhanced risk persists as long as immunosuppression is continued, albeit at a lower frequency [80••]. During the 2009 H1N1 pandemic, hospitalization rates reached $71 \%$ in SOT recipients and caused the death of $4 \%$ [81]. Because influenza is a respiratory tract infection, and because of higher immunosuppression, lung transplant recipients are especially at high risk of developing complications, such as bronchiolitis obliterans, a major cause of mortality [7, 82]. For all these reasons, annual immunization of SOT as well as HSCT recipients and their household remains a good preventive measure $[81,82]$. The efficacy of immunization depends on the match between the vaccine strain and the circulating strain during the influenza season [47]. Two different types of influenza vaccines exist. The first one is a trivalent inactivated vaccine (TIAV) containing $2 \mathrm{~A}$ and $1 \mathrm{~B}$ strain; recently, a similar quadrivalent vaccine received approval providing additional protection against an influenza B strain [47]. The second type is a LAIV which appears to induce a better seroconversion rate and longer protection than the inactivated vaccine [83]. This LAVV is currently available and recommended in children and adults between 5 and 59 years old, in several countries such as the USA, Canada, and Japan; it is not approved for use in immunosuppressed patients [84-86]. However, individuals immunized with LAIV should avoid contact with immunocompromised hosts for 1 week because of the risk of vaccine strain shedding [87]. Children as young as 6 months of age can be immunized with TIAV with good protection rates $[9,85,86]$. TIAV is also recommended in SOT and HSCT recipients because it is considered a safer vaccine in this population [79]. During the influenza season, the TIAV vaccine is recommended as soon as 3 months after SOT and HSCT [47]. Despite variations in immunogenicity and efficacy of the vaccine after transplantation, TIAV seems safe and does not trigger graft rejection in these patients $[81,88,89]$. 


\section{Yellow Fever Vaccine}

Yellow fever (YF) is a tropical disease transmitted by mosquitoes and found in Africa and Latin America. The clinical spectrum varies from asymptomatic to a devastating hemorrhagic disease, which can lead to YF-associated viscerotropic disease and causes 30,000 deaths annually worldwide [90, 91]. No treatment is available, which is the reason why vaccination is recommended to every person living or traveling to endemic regions [92]. The only available vaccine is the 17D YF live attenuated vaccine $[2,5,7]$. Despite its overall safety, several extremely rare cases of viscerotropic disease following the YF vaccine have been reported [93, 94]. The vaccine should be given to all healthy individuals older than 9month-old living or traveling to an endemic area [92]. No YF infection has been reported in SOT or HSCT recipients to our knowledge. Very few data are available on YF vaccine in immunocompromised hosts. One kidney transplant patient was immunized with a YF vaccine by mistake and had consequently a perturbation of liver function tests [91]. The patient received intravenous immunoglobulins and rapidly recovered. Two patients received YF vaccine more than 2 years after HSCT, reported no adverse event and acceptable seroprotection [90, 95]. In HIV-positive treated patients, YF vaccine is strongly recommended prior to traveling to a region where YF is endemic $[96,97]$. However, vaccination should be avoided in patients with low CD4 count [98]. One retrospective study in Brazil reported that 19 SOT recipients received the YF vaccine with no serious adverse events [99]. SOT recipients should, if possible, not travel to endemic areas, and, if exposure is likely, the benefits of YF immunization should be evaluated and a decision should be taken carefully on a case-to-case basis [87].

\section{Polio Vaccine}

Thanks to a considerable effort in worldwide vaccination, the incidence of polio has declined in a spectacular fashion. However, smaller epidemic outbreaks are found in several countries, such as Nigeria, Pakistan, and Afghanistan [100]. Two kinds of vaccines are available: the inactivated polio vaccine (IPV) which is recommended in developed countries, as well as in SOT and HSCT recipients [16], and the live attenuated oral poliomyelitis vaccine (OPV), particularly recommended in developing countries because of its ease of administration, its cost, as well as its capacity to induce indirect protection by spreading through fecal-oral contact [101]. Unfortunately, the latter reason can occasionally induce outbreaks of vaccineassociated poliomyelitis, and SOT's household members should therefore not receive OPV [1]. No data are available regarding OPV vaccine in SOT recipient patients because IPV is a better option. In SOT recipients traveling to endemic area, IPV booster should be given before traveling [1].

\section{Japanese Encephalitis Vaccine}

Japanese encephalitis (JE) is a virus transmitted by mosquitoes in Asia and the western Pacific and causes a severe neurologic disease with long-term deficit or death. No treatment is available and the only way to be protected from this disease is indirect protection from mosquitoes and immunization. Two inactivated vaccines (mouse brain-derived and Vero cell culture-derived) and two LAVV (chimeric vaccine and SA 1414-2) are currently available [102]. The first is costly as well as insufficiently immunologic, requiring initially several doses and boosters to trigger a strong and long-term seroprotection [103, 104]. The second was licensed in 1998 and was widely used in China but is by now replaced by the SA 14-14-2 LAVV. Since 2009, it is authorized in many countries such as the USA, Europe, and Switzerland [102, 103]. The third vaccine, the new live attenuated chimeric vaccine, is produced with the same vector as the YF vaccine 17D. Recent studies show a good safety profile and satisfactory seroprotection with a single dose, and this vaccine is now available in Australia and Thailand [102]. The SA 14-14-2 LAVV appears to be safe and to have a good efficacy in children and adults by providing $80-96 \%$ of seroconversion with one dose and almost complete protection with two doses [104-106]. This vaccine is also cheap to produce and is the most commonly used in endemic areas [102]. Currently, no data are available regarding the safety of any of these four JE vaccines in SOT or HSCT recipients to our knowledge. Only one recent study used the SA 14-14-2 LAVV and showed a high seroconversion rate and a good safety profile in HSCT patients after two doses [107•]. However, further studies are needed and meanwhile inactivated JE vaccine should be preferred in transplant recipients.

\section{Conclusion}

As in other significantly immunocompromised patients, LAVV are currently contraindicated in SOT as well as during the first 2 years following transplantation in HSCT recipients. However, vaccination opportunities in this specific population are often missed or delayed, mostly because of complicated recommendations, temporary or perceived contraindications, and lack of knowledge [18, 108]. The fear of vaccineassociated disease after LAVV immunization is mostly theoretical, and it is necessary to repeatedly question these recommendations with newly available studies and reports. It remains important to evaluate the immunization options according to the level of immunosuppressive regimen, the time after 
the transplantation, as well as the underlying disease, and decide on a case-by-case basis [5, 87]. The acceptable risks and expected benefits to immunize with a LAVV should be put into perspective, because in some cases, when exposed, patients may develop severe complications of these preventable diseases.

Are LAVV in transplant recipients friends or foes? They are often not foes but not quite friends either. Immunizing transplant patients with LAVV may be beneficial and probably safe in selected patients, at least 1 year after SOT and 2 years after HSCT, with a controlled underlying disease, and low levels of immunosuppression. However, to allow changes in international guidelines, further studies are needed in larger populations to assess the safety of LAVV, the cellular and humoral immune response to vaccination, as well as the long-term follow-up to estimate the maintenance of lasting protection.

\section{Compliance with Ethics Guidelines}

Conflict of Interest Klara Posfay-Barbe and Charlotte Verolet declare no conflicts of interest.

Human and Animal Rights and Informed Consent This article does not contain any studies with human or animal subjects performed by the author.

\section{References}

Papers of particular interest, published recently, have been highlighted as:

- Of importance

•- Of major importance

1. Stark K, Gunther M, Schonfeld C, et al. Immunisations in solidorgan transplant recipients. Lancet. 2002;359:957-65.

2. Wyplosz B, Van der Vliet D, Consigny PH, et al. Vaccinations for the traveling adult solid organ transplant recipient (excluding hematopoietic stem cell transplant recipients). Med Mal Infect. 2009;39:225-33.

3. Shetty AK, Winter MA. Immunization of children receiving immunosuppressive therapy for cancer or hematopoietic stem cell transplantation. Ochsner J. 2012;12:228-43.

4. Wingard JR, Hsu J, Hiemenz JW. Hematopoietic stem cell transplantation: an overview of infection risks and epidemiology. Hematol Oncol Clin North Am. 2011;25:101-16.

5. Pirofski LA, Casadevall A. Use of licensed vaccines for active immunization of the immunocompromised host. Clin Microbiol Rev. 1998;11:1-26.

6. Kano H, Mizuta K, Sakakihara Y, et al. Efficacy and safety of immunization for pre- and post-liver transplant children. Transplantation. 2002;74:543-50.

7. Kumar D. Immunizations following solid-organ transplantation. Curr Opin Infect Dis. 2014;27:329-35.

8.• Rubin LG, Levin MJ, Ljungman P, et al. 2013 IDSA clinical practice guideline for vaccination of the immunocompromised host. Clin Infect Dis. 2014;58:309-18. Excellent updated review of the guidelines for vaccination of immunocompromised adults and children.

9. Kumar D, Blumberg EA, Danziger-Isakov L, et al. Influenza vaccination in the organ transplant recipient: review and summary recommendations. Am J Transplant. 2011;11:2020-30.

10. Kumar D, Morris MI, Kotton CN, et al. Guidance on novel influenza $\mathrm{A} / \mathrm{H} 1 \mathrm{~N} 1$ in solid organ transplant recipients $\dagger$. Am J Transplant. 2010;10:18-25.

11. Parham P. The immune system. Garland Science. 2009; third edition: 455.

12. Plotkin SA. Correlates of protection induced by vaccination. Clin Vaccine Immunol. 2010;17:1055-65.

13. Plotkin SA. Vaccines, vaccination, and vaccinology. J Infect Dis. 2003; 187:1349-59.

14. Danziger-Isakov L, Evans HM, Green M, et al. Capacity building in pediatric transplant infectious diseases: an international perspective. Pediatr Transplant. 2014;18:790-3.

15. Pittet LF, Posfay-Barbe KM. Immunization in transplantation: review of the recent literature. Curr Opin Organ Transplant. 2013;18(5):543-8.

16. Lopez MJ, Thomas S. Immunization of children after solid organ transplantation. Pediatr Clin North Am. 2003;50:1435-49.

17. Posfay-Barbe KM, Siegrist CA. Immunization and transplantation-what is new and what is coming? Pediatr Transplant. 2009;13:404-10.

18. Diana A, Posfay-Barbe KM, Belli DC, et al. Vaccine-induced immunity in children after orthotopic liver transplantation: a 12yr review of the Swiss national reference center. Pediatr Transplant. 2007;11:31-7.

19. L'Huillier AG, Wildhaber BE, Belli DC, et al. Successful serology-based intervention to increase protection against vaccine-preventable diseases in liver-transplanted children: a 19$\mathrm{yr}$ review of the Swiss national reference center. Pediatr Transplant. 2012;16:50-7.

20. Burroughs M, Moscona A. Immunization of pediatric solid organ transplant candidates and recipients. Clin Infect Dis. 2000;30: 857-69.

21. Sester M, Gartner BC, Girndt M, et al. Vaccination of the solid organ transplant recipient. Transplant Rev (Orlando). 2008;22: 274-84.

22. Danziger-Isakov L, Posfay-Barbe KM. Optimal approach to immunization in pediatric solid organ transplantation. Pediatr Transplant. 2012;16:680-3.

23. Shinjoh M, Miyairi I, Hoshino K, et al. Effective and safe immunizations with live-attenuated vaccines for children after living donor liver transplantation. Vaccine. 2008;26:6859-63.

24. Ljungman P, Cordonnier C, Einsele H, et al. Vaccination of hematopoietic cell transplant recipients. Bone Marrow Transplant. 2009;44:521-6.

25. Machado CM. Reimmunization after hematopoietic stem cell transplantation. Expert Rev Vaccines. 2005;4:219-28.

26. Ariza-Heredia EJ, Gulbis AM, Stolar KR, et al. Vaccination guidelines after hematopoietic stem cell transplantation: practitioners' knowledge, attitudes, and gap between guidelines and clinical practice. Transpl Infect Dis. 2014. doi:10.1111/tid.12312.

27. Avery RK. Immunizations in adult immunocompromised patients: which to use and which to avoid. Cleve Clin J Med. 2001;68:33748.

28. Pauksen K, Duraj V, Ljungman P, et al. Immunity to and immunization against measles, rubella and mumps in patients after autologous bone marrow transplantation. Bone Marrow Transplant. 1992;9:427-32.

29. Sauerbrei A, Prager J, Hengst U, et al. Varicella vaccination in children after bone marrow transplantation. Bone Marrow Transplant. 1997;20:381-3. 
30. Styczynski J, Gil L, Party EPDW. Prevention of infectious complications in pediatric HSCT. Bone Marrow Transplant. 2008;42 Suppl 2:S77-81.

31. Inaba H, Hartford CM, Pei D, et al. Longitudinal analysis of antibody response to immunization in paediatric survivors after allogeneic haematopoietic stem cell transplantation. Br J Haematol. 2012;156:109-17.

32. Danziger-Isakov L, Kumar D, Practice ASTIDCo. Vaccination in solid organ transplantation. Am J Transplant. 2013;13 Suppl 4: 311-7.

33.• Posfay-Barbe KM, Pittet LF, Sottas C, et al. Varicella-zoster immunization in pediatric liver transplant recipients: safe and immunogenic. Am J Transplant. 2012;12:2974-85. A significant interventional study which measured both humoral and cell-mediated immunity to VZV immunization in pediatric liver transplant recipients.

34. Office fédéral de la santé publique. Vaccination contre la varicelle. Recommandations dela Commission suisse pour les vaccinations (CSV) et de l'Office fédéral de la santé publique (OFSP). Bull OFSP. 2004;45:846-8.

35. Feldhoff CM, Balfour Jr HH, Simmons RL, et al. Varicella in children with renal transplants. J Pediatr. 1981;98:25-31.

36. Geel A, Zuidema W, van Gelder T, et al. Successful vaccination against varicella zoster virus prior to kidney transplantation. Transplant Proc. 2005;37:952-3.

37. Fehr T, Bossart W, Wahl C, et al. Disseminated varicella infection in adult renal allograft recipients: four cases and a review of the literature. Transplantation. 2002;73:608-11.

38. Furth SL, Neu AM, Sullivan EK, et al. Immunization practices in children with renal disease: a report of the North American Pediatric Renal Transplant Cooperative Study. Pediatr Nephrol. 1997;11:443-6.

39. McGregor RS, Zitelli BJ, Urbach AH, et al. Varicella in pediatric orthotopic liver transplant recipients. Pediatrics. 1989;83:256-61.

40. Weinstock DM, Boeckh M, Boulad F, et al. Postexposure prophylaxis against varicella-zoster virus infection among recipients of hematopoietic stem cell transplant: unresolved issues. Infect Control Hosp Epidemiol. 2004;25:603-8.

41. Banovic T, Yanilla M, Simmons R, et al. Disseminated varicella infection caused by varicella vaccine strain in a child with low invariant natural killer T cells and diminished CD1d expression. J Infect Dis. 2011;204:1893-901.

42. Prelog M, Zimmerhackl LB. Varicella vaccination in pediatric kidney and liver transplantation. Pediatr Transplant. 2010;14:417.

43. Broyer M, Tete MJ, Guest G, et al. Varicella and zoster in children after kidney transplantation: long-term results of vaccination. Pediatrics. 1997;99:35-9.

44. Mizuta K, Urahashi T, Ihara Y, et al. Varicella zoster virus disease after pediatric living donor liver transplantation: is it serious? Transplant Proc. 2012;44:780-3.

45. Kraft JN, Shaw JC. Varicella infection caused by Oka strain vaccine in a heart transplant recipient. Arch Dermatol. 2006;142:9435.

46. Levitsky J, Te HS, Faust TW, et al. Varicella infection following varicella vaccination in a liver transplant recipient. Am J Transplant. 2002;2:880-2.

47. Kotton CN. Immunization after kidney transplantation - what is necessary and what is safe? Nat Rev Nephrol. 2014;10(10):55562.

48. Weinberg A, Horslen SP, Kaufman SS, et al. Safety and immunogenicity of varicella-zoster virus vaccine in pediatric liver and intestine transplant recipients. Am J Transplant. 2006;6:565-8.

49. Zamora I, Simon JM, Da Silva ME, et al. Attenuated varicella virus vaccine in children with renal transplants. Pediatr Nephrol. 1994;8:190-2.
50. Chaves Tdo S, Lopes MH, de Souza VA, et al. Seroprevalence of antibodies against varicella-zoster virus and response to the varicella vaccine in pediatric renal transplant patients. Pediatr Transplant. 2005;9:192-6.

51. Khan S, Erlichman J, Rand EB. Live virus immunization after orthotopic liver transplantation. Pediatr Transplant. 2006;10:7882.

52. Ljungman P, Wang FZ, Nilsson C, et al. Vaccination of autologous stem cell transplant recipients with live varicella vaccine: a pilot study. Support Care Cancer. 2003;11:739-41.

53. Sasadeusz J, Prince HM, Schwarer A, et al. Immunogenicity and safety of a two-dose live attenuated varicella vaccine given to adults following autologous hematopoietic stem cell transplantation. Transpl Infect Dis. 2014. doi:10.1111/tid. 12295. An interesting interventional study showing that the VZV vaccine is safe but not immunogenic when administered early after HSCT.

54. Chou JF, Kernan NA, Prockop S, et al. Safety and immunogenicity of the live attenuated varicella vaccine following $\mathrm{T}$ replete or $\mathrm{T}$ cell-depleted related and unrelated allogeneic hematopoietic cell transplantation (alloHCT). Biol Blood Marrow Transplant. 2011;17:1708-13.

55. Kussmaul SC, Horn BN, Dvorak CC, et al. Safety of the live, attenuated varicella vaccine in pediatric recipients of hematopoietic SCTs. Bone Marrow Transplant. 2010;45:1602-6.

56. Bhalla P, Forrest GN, Gershon M, et al. Disseminated persistent and fatal infection due to the vaccine strain (vOka) of varicellazoster virus in an adult following stem cell transplantation. Clin Infect Dis. 2014; ciu970.

57. Mullane KM, Winston DJ, Wertheim MS, et al. Safety and immunogenicity of heat-treated zoster vaccine (ZVHT) in immunocompromised adults. J Infect Dis. 2013;208:1375-85.

58. Avery RK, Michaels M. Update on immunizations in solid organ transplant recipients: what clinicians need to know. Am J Transplant. 2008;8:9-14.

59. Naidus E, Damon L, Schwartz BS, et al. Experience with use of Zostavax ${ }^{\mathbb{R}}$ in patients with hematologic malignancy and hematopoietic cell transplant recipients. Am J Hematol. 2012;87:123-5.

60. Issa NC, Marty FM, Leblebjian H, et al. Live attenuated varicellazoster vaccine in hematopoietic stem cell transplantation recipients. Biol Blood Marrow Transplant. 2014;20:285-7. A large interventional study looking at the Herpes Zoster vaccine immunization in HSCT patients.

61. Hata A, Asanuma H, Rinki M, et al. Use of an inactivated varicella vaccine in recipients of hematopoietic-cell transplants. N Engl J Med. 2002;347:26-34.

62. Redman RL, Nader S, Zerboni L, et al. Early reconstitution of immunity and decreased severity of herpes zoster in bone marrow transplant recipients immunized with inactivated varicella vaccine. J Infect Dis. 1997;176:578-85.

63. Stadtmauer EA, Sullivan KM, Marty FM, et al. A phase 1/2 study of an adjuvanted varicella-zoster virus subunit vaccine in autologous hematopoietic cell transplant recipients. Blood. 2014;124: 2921-9.

64. Kalman S, Bakkaloglu SA, Ozkaya O, et al. Measles: a rare communicable disease in a child with renal transplantation. Pediatr Transplant. 2002;6:432-4.

65. Gastanaduy PA, Redd SB, Fiebelkorn AP, et al. Measles-United States, January 1-May 23, 2014. MMWR Morb Mortal Wkly Rep. 2014;63:496-9.

66. National Center for Immunization and Respiratory Diseases DoVD, Division of Viral Diseases. Measles cases and outbreaks. 2015. Available at: http://www.cdc.gov/measles/cases-outbreaks. html 
67. Kidd IM, Booth CJ, Rigden SP, et al. Measles-associated encephalitis in children with renal transplants: a predictable effect of waning herd immunity? Lancet. 2003;362:832.

68. Sternfeld T, Spori-Byrtus V, Riediger C, et al. Acute measles infection triggering an episode of liver transplant rejection. Int $\mathrm{J}$ Infect Dis. 2010;14:e528-30.

69. Young MK, Nimmo GR, Cripps AW, et al. Post-exposure passive immunisation for preventing measles. Cochrane Database Syst Rev. 2014;4, CD010056.

70. Baas MC, van Donselaar KA, Florquin S, et al. Mumps: not an innocent bystander in solid organ transplantation. Am J Transplant. 2009;9:2186-9.

71. Mazariegos GV, Green M, Reyes J, et al. Rubella infection after orthotopic liver transplantation. Pediatr Infect Dis J. 1994;13:1612.

72. Eyre TA, Pelosi E, McQuaid S, et al. Mumps virus encephalomyelitis in a 19-year old male patient with an undefined severe combined immunodeficiency post-haematopoietic bone marrow transplantation: a rare fatal complication. J Clin Virol. 2013;57:165-8.

73. Campbell AL, Herold BC. Immunization of pediatric solid-organ transplantation candidates: immunizations in transplant candidates. Pediatr Transplant. 2005;9:652-61.

74. Rand EB, McCarthy CA, Whitington PF. Measles vaccination after orthotopic liver transplantation. J Pediatr. 1993;123:87-9.

75. Machado CM, Goncalves FB, Pannuti CS, et al. Measles in bone marrow transplant recipients during an outbreak in Sao Paulo, Brazil. Blood. 2002;99:83-7.

76. Machado CM, de Souza VA, Sumita LM, et al. Early measles vaccination in bone marrow transplant recipients. Bone Marrow Transplant. 2005;35:787-91.

77. Shaw PJ, Bleakley M, Burgess M. Safety of early immunization against measles/mumps/rubella after bone marrow transplantation. Blood. 2002;99:3486.

78. Pauksen K, Linde A, Lonnerholm G, et al. Influence of the specific $\mathrm{T}$ cell response on seroconversion after measles vaccination in autologous bone marrow transplant patients. Bone Marrow Transplant. 1996;18:969-73.

79. Cordero E, Manuel O. Influenza vaccination in solid-organ transplant recipients. Curr Opin Organ Transplant. 2012;17:601-8.

$80 . \bullet$ Ison MG. Influenza prevention and treatment in transplant recipients and immunocompromised hosts. Influenza Other Respir Viruses. 2013;7 Suppl 3:60-6. An excellent update on influenza's epidemiology, prevention through immunization, and antiviral prophylaxis and treatment in immunocompromised patients.

81. Manuel O, Humar A, Berutto C, et al. Low-dose intradermal versus intramuscular trivalent inactivated seasonal influenza vaccine in lung transplant recipients. J Heart Lung Transplant. 2011;30: $679-84$

82. Manuel O, Humar A, Chen MH, et al. Immunogenicity and safety of an intradermal boosting strategy for vaccination against influenza in lung transplant recipients. Am J Transplant. 2007;7:256772.

83. Ambrose CS, Walker RE, Connor EM. Live attenuated influenza vaccine in children. Semin Pediatr Infect Dis. 2006;17:206-12.

84. Office fédéral de la santé publique, Commission fédérale pour les vaccinations (CFV), Groupe de travail Influenza (GTI). Directives et recommandations. Recommandations pour la vaccination contre la grippe. Berne: Office Fédéral de la Santé Publique, 2011.

85. Moore DL, Canadian Paediatric Society ID. Immunization C. Vaccine recommendations for children and youth for the 2014/ 2015 influenza season. Paediatr Child Health. 2014;19:440-4.

86. Committee On Infectious D, Committee On Infectious D. Recommendations for prevention and control of influenza in children, 2014-2015. Pediatrics. 2014;134:e1503-19.
87. Abuali MM, Arnon R, Posada R. An update on immunizations before and after transplantation in the pediatric solid organ transplant recipient. Pediatr Transplant. 2011;15:770-7.

88. Vermeiren P, Aubert V, Sugamele R, et al. Influenza vaccination and humoral alloimmunity in solid organ transplant recipients. Transpl Int. 2014;27:903-8

89. Candon S, Thervet E, Lebon P, et al. Humoral and cellular immune responses after influenza vaccination in kidney transplant recipients. Am J Transplant. 2009;9:2346-54.

90. Gowda R, Cartwright K, Bremner JA, et al. Yellow fever vaccine: a successful vaccination of an immunocompromised patient. Eur J Haematol. 2004;72:299-301.

91. Slifka MK, Hammarlund E, Lewis MW, et al. Antiviral immune response after live yellow fever vaccination of a kidney transplant recipient treated with IVIG. Transplantation. 2013;95:e59-61.

92. Monath TP, Vasconcelos PF. Yellow fever. J Clin Virol. 2014;S1386-6532(14):00369-2.

93. Gerasimon G, Lowry K. Rare case of fatal yellow fever vaccineassociated viscerotropic disease. South Med J. 2005;98:653-6.

94. Vasconcelos PF, Luna EJ, Galler R, et al. Serious adverse events associated with yellow fever 17DD vaccine in Brazil: a report of two cases. Lancet. 2001;358:91-7.

95. Yax JA, Farnon EC, Cary EN. Successful immunization of an allogeneic bone marrow transplant recipient with live, attenuated yellow fever vaccine. J Travel Med. 2009;16:365-7.

96. Barte H, Horvath TH, Rutherford GW. Yellow fever vaccine for patients with HIV infection. Cochrane Database Syst Rev. 2014;1, CD010929.

97. Pistone $\mathrm{T}$, Verdiere $\mathrm{CH}$, Receveur $\mathrm{MC}$, et al. Immunogenicity and tolerability of yellow fever vaccination in 23 French HIV-infected patients. Curr HIV Res. 2010;8:461-6.

98. Kengsakul K, Sathirapongsasuti K, Punyagupta S. Fatal myeloencephalitis following yellow fever vaccination in a case with HIV infection. J Med Assoc Thai. 2002;85:131-4.

99. Azevedo LS, Lasmar EP, Contieri FL, et al. Yellow fever vaccination in organ transplanted patients: is it safe? A multicenter study. Transpl Infect Dis. 2012;14:237-41.

100. Who. Polio vaccines: WHO position paper, January 2014 -recommendations. Vaccine. 2014;32:4117-8.

101. Prevots DR, Burr RK, Sutter RW, et al. Poliomyelitis prevention in the United States. Updated recommendations of the Advisory Committee on Immunization Practices (ACIP). MMWR Recomm Rep. 2000;49:1-22. quiz CE21-27.

102. Yun SI, Lee YM. Japanese encephalitis: the virus and vaccines. Hum Vaccine Immunother. 2014;10:263-79.

103. Organization WH. Japanese encephalitis surveillance and immunization-Asia and the western Pacific 2012. MMWR Morb Mortal Wkly Rep. 2013;62:658-62.

104. Griffiths MJ, Turtle L, Solomon T. Japanese encephalitis virus infection. Handb Clin Neurol. 2014;123:561-76.

105. Hennessy S, Liu Z, Tsai TF, et al. Effectiveness of live-attenuated Japanese encephalitis vaccine (SA14-14-2): a case-control study. Lancet. 1996;347:1583-6.

106. Tsai TF, Yu YX, Jia LL, et al. Immunogenicity of live attenuated SA14-14-2 Japanese encephalitis vaccine - a comparison of 1- and 3-month immunization schedules. J Infect Dis. 1998;177:221-3.

107. Pakakasama S, Wattanatitan S, Techasaensiri C, et al. Immunogenicity of a live-attenuated Japanese encephalitis vaccine in children and adolescents after hematopoietic stem cell transplantation. Bone Marrow Transplant. 2014;49:1307-9. The first interventional study on JE (SA 14-14-12) immunization in transplant patients.

108. Lerchenfeldt SM, Cronin SM, Chandrasekar PH. Vaccination adherence in hematopoietic stem cell transplant patients: a pilot study on the impact of vaccination cards and reminder telephone calls. Transpl Infect Dis. 2013;15:634-8. 
109. Ljungman P, Fridell E, Lonnqvist B, et al. Efficacy and safety of vaccination of marrow transplant recipients with a live attenuated measles, mumps, and rubella vaccine. J Infect Dis. 1989;159:610-5.
110. King SM, Saunders EF, Petric M, et al. Response to measles, mumps and rubella vaccine in paediatric bone marrow transplant recipients. Bone Marrow Transplant. 1996;17:633-6. 